IZA DP No. 7209

A Goodness-of-Fit Approach to Estimating Equivalence Scales

Martin Biewen

Andos Juhasz

January 2013 


\title{
A Goodness-of-Fit Approach to Estimating Equivalence Scales
}

\author{
Martin Biewen \\ University of Tübingen, \\ IZA and DIW Berlin
}

Andos Juhasz

University of Tübingen

\section{Discussion Paper No. 7109 \\ February 2013}

\author{
IZA \\ P.O. Box 7240 \\ 53072 Bonn \\ Germany \\ Phone: +49-228-3894-0 \\ Fax: +49-228-3894-180 \\ E-mail: iza@iza.org
}

Any opinions expressed here are those of the author(s) and not those of IZA. Research published in this series may include views on policy, but the institute itself takes no institutional policy positions. The IZA research network is committed to the IZA Guiding Principles of Research Integrity.

The Institute for the Study of Labor (IZA) in Bonn is a local and virtual international research center and a place of communication between science, politics and business. IZA is an independent nonprofit organization supported by Deutsche Post Foundation. The center is associated with the University of Bonn and offers a stimulating research environment through its international network, workshops and conferences, data service, project support, research visits and doctoral program. IZA engages in (i) original and internationally competitive research in all fields of labor economics, (ii) development of policy concepts, and (iii) dissemination of research results and concepts to the interested public.

IZA Discussion Papers often represent preliminary work and are circulated to encourage discussion. Citation of such a paper should account for its provisional character. A revised version may be available directly from the author. 


\section{ABSTRACT}

\section{A Goodness-of-Fit Approach to Estimating Equivalence Scales ${ }^{1}$}

We use income satisfaction data in order to estimate equivalence scales. Our method differs from previous attempts to use satisfaction data for this purpose in that it can be used to estimate or evaluate any given parametric equivalence scale. It can also be employed to investigate specific questions related to equivalence scales such as whether these scales are income-dependent or to what extent they depend on specific household characteristics such as whether some household members are in a partner relationship. A further advantage of our approach is that, within a first-differencing nonlinear least-squares framework, we can carry out full statistical inference about the hypotheses under consideration. Our empirical results suggest that household economies of scale are higher than those assumed in commonly used scales such as the OECD or the Luxembourg scale. We also obtain the novel empirical result that economies of scale may decrease (rather than increase) in income, which is what one would expect if the share of consumption goods generating economies of scale (such as housing) decreases with income.

JEL Classification: J31, J71, C02, D31

Keywords: income satisfaction, economies of scale, nonlinear least squares

Corresponding author:

Martin Biewen

Department of Economics

University of Tübingen

Mohlstr. 36

72074 Tübingen

Germany

E-mail: martin.biewen@uni-tuebingen.de

\footnotetext{
${ }^{1}$ We are grateful to Andrew Oswald for helpful discussions and suggestions, and to Carsten Schröder for help with the literature. The data used in this paper (SOEP v27, 1998-2010) were made available by the German Socio-Economic Panel Study (SOEP) at the German Institute for Economic Research (DIW), Berlin
} 


\section{Introduction}

Equivalence scales are used to make the utility of income comparable across heterogeneous households. They thus play a crucial role in various fields of welfare and public economics such as the measurement of inequality and poverty, or the design of tax- and welfare systems. In principle, three main approaches have been used to construct or estimate equivalence scales. ${ }^{2}$ The first approach is based on the estimation of consumer demand systems (see, e.g., Muellbauer, 1980, Pashardes, 1995, and Pendakur, 1999). As shown by Blundell/Lewbel (1991), this approach is challenged by identification problems unless additional assumptions are made. One such assumption is that the equivalence scale is independent of reference income ('Independence of Base Assumption', Lewbel, 1989, Blackorby/Donaldson, 1993). More general restrictions have been suggested by Donaldson/Pendakur $(2003,2006)$. A second approach is based on subjective data on income or life satisfaction. In one variant, this approach uses survey data that directly lets respondents describe which income levels they associate with different levels of welfare (e.g., van Praag, 1968, 1991, Kapteyn/van Praag, 1976, Koulovatianos et al., 2005). A drawback of this approach is that respondents are asked to make assessments of situations that may be hypothetical to them. This drawback is not present in the second variant of the subjective approach which only uses information on how satisfied respondents are with their own factual income (e.g., Melenberg/van Soest, 1996, Bellemare et al. 2002, Schwarze, 2003, and Bollinger et al., 2012). The third approach to constructing equivalence scales is an ad-hoc one. It uses 'expert' assessments or more or less arbitrary rules-of-thumb in order to define the weights different household members receive in the equivalence scale. Examples are the so-called OECD equivalence scale or the Luxembourg (= square-root) equivalence scale (see Atkinson et al., 1995, or OECD, 2005). Although this latter approach is less evidence-based than the first two approaches, the equivalence scales resulting from it are by far the most widely used ones in practice.

In this paper, we contribute to the second line of research, i.e. we use income satisfaction data in order to estimate equivalence scales. Our approach differs from previous approaches in that it can be used to estimate or evaluate any parametric equivalence scale. We use the simple idea that there should be some relationship between income satisfaction and equivalized income, i.e. the household income as perceived by an individual in a household with a given structure. This relationship will only be correctly specified if the correct equivalence scale is used in order to compute equivalized income from household income. As the correctly equivalized income is

\footnotetext{
${ }^{2}$ See Lewbel/Pendakur (2008a) and Schröder (2009) for overviews.
} 
a nonlinear function of the equivalence scale, this leads to a nonlinear least squares problem which we implement on first-differenced data in order to eliminate time-invariant unobserved heterogeneity. ${ }^{3}$ Given the parametric nature of our procedure, we can carry out full statistical inference about equivalence scale parameters and related hypotheses such as whether equivalence scales are income dependent or how they depend on specific household features. For example, we can test whether the exact ages of household members matter, or whether the equivalence scale crucially depends on whether some of the household members are partners. The latter was suggested by Bollinger et al. (2012) who argue that in this case, household economies of scale should be much higher because partners are likely to share the same room, the same bed etc.

Our empirical results suggest that commonly used equivalence scales such as the OECD equivalence scale or the Luxembourg equivalence scale underestimate household economies of scale. The economies of scale of living together in a household as perceived by the household members in terms of income satisfaction appear to be substantially higher than for example embodied in the square-root rule provided by Luxembourg equivalence scale. As in Bollinger et al. (2012), we also find that the economies of scale in the case of a couple living in one household may be very large so that in some cases 'two can live as cheaply as one'. Contrary to some results in the literature, we find that household economies of scale may decrease with reference income which is what one would expect if the share of expenditures generating economies of scale (such as housing) decreases in income. We find that this is true for adults but not for children, for whom economies of scale increase with income to a certain extent. We also investigate how estimates of poverty and inequality are affected if the equivalence scales resulting from our method rather than standard equivalence scales such as the OECD or Luxembourg scale are used. We find that using the estimated scales may make a substantial difference.

The rest of this paper is structured as follows. In section 2, we discuss some related literature. Section 3 describes our econometric setup. Section 4 introduces the data used in our empirical analysis. In section 5, we present our empirical results. Section 6 concludes.

\footnotetext{
${ }^{3}$ For a similar idea used in the context of poverty line estimation, see Juhasz (2012).
} 


\section{Related literature}

We briefly review some related literature. We concentrate on contributions that either use subjective income evaluation data or that are concerned with whether or not equivalence scales are income dependent. The subjective approach to estimating equivalence scales was pioneered by van Praag (1968) and has generated a large literature, see for example Kapteyn/van Praag (1976), van Praag/van der Sar (1988), and van Praag (1991) (also called the 'Leyden school'). The idea of this approach is to use survey data in which respondents explicitly state what income level they would consider as a) very bad, b) bad, c) insufficient, d) sufficient, e) good, and f) very good. This data is then used to estimate a household cost function (of a particular parametric form), which can be used to derive household equivalence scales. The equivalence scales resulting from this method are typically quite flat, i.e. imply large economies of scale and small marginal costs for additional household members (see the discussion in Melenberg/van Soest, 1996).

A related but different approach is followed by Koulovatianos et al. (2005) who directly ask survey participants how they think equivalence scales look like for different levels of reference income. They can thus directly investigate whether equivalence scales are income dependent and what form this dependence takes. Their results suggest that equivalence scales decline with income, implying that economies of scale are larger for richer households. Another advantage of their approach is that they can directly test whether the relationship between equivalence scales and income satisfies restrictions needed to identify equivalence scales from consumption data such as 'Generalized Equivalence Exactness' (GESE, Donaldson/Pendakur, 2003). Koulovatianos et al. (2005) find evidence in favor of such restrictions.

Melenberg/van Soest (1996) and Bellemare et al. (2002) are two examples for studies which use data on actual income satisfaction in order to estimate equivalence scales. The advantage of this approach over the ones described in the previous two paragraphs is that it only uses subjective assessments of situations the respondents actually experience rather than of situations that may be very hypothetical to them. The focus of Melenberg/van Soest (1996) and Bellemare et al. (2002) is on the semi-parametric modeling of the relationship between income satisfaction and household income. ${ }^{4}$ They conclude that simple parametric models of income satisfaction like the ordinal probit model are generally rejected in favor of more nonparametric alternatives, but

\footnotetext{
${ }^{4}$ Melenberg/van Soest (1996) also provide a comparison of the income satisfaction approach with that of the 'Leyden school'.
} 
that estimated equivalence scales do not depend much on what model and estimation method is chosen.

Schwarze (2003) seems to be the first one to use panel data for estimating an equivalence scale from income satisfaction data. Using panel data makes it possible to control for time-invariant correlated unobserved heterogeneity in the determinants of income satisfaction, which appears to be a highly relevant point. More concretely, Schwarze (2003) estimates the economies of scale parameter in what we call a Luxembourg-type scale below by using a fixed-effects logit model after collapsing income satisfaction into a zero/one-indicator. Schwarze's approach is related to the method we use below, but is restricted to the particularly simple form of the Luxembourg-type scale (which results in a linear form after taking the log).

Bollinger et al. (2012) use panel data on both income satisfaction and general life satisfaction in order to estimate equivalence scales. They use fixed-effects and random-effects ordered probit and logit models in order to control for unobserved heterogeneity. Their main point is that household economies of scale may be much larger than commonly assumed, especially if there are partners in the household who can share goods to a much larger extent than non-partners. Bollinger et al.'s method is less general than ours as it requires the equivalence scale to be of a particular form in order to fit into their framework which is based on the 'Independence of Base Assumption' (Lewbel, 1989, Blackorby/Donaldson, 1993). ${ }^{5}$

There is a large number of papers that have tested the 'Independence of Base Assumption' using consumption data and parametric or nonparametric demand systems. Parametric papers (Blundell/Lewbel, 1991, Dickens et al., 1993, and semiparametric papers (Blundell et al., 1998, Pendakur, 1999) generally clearly reject the independence of base assumption. The evidence in Pendakur (1999) suggests that it may hold for some household types but not for others, especially those with children. Donaldson/Pendakur (2003) relax the independence of base assumption by allowing for certain kinds of dependencies between the equivalence scale and reference income ('Generalized Equivalence Exactness', GESE). Although they find that their assumption of GESE does not exactly hold in their data, their empirical results suggest that household economies of scale increase with reference income, especially for households with children. Finally, De Ree et al. (2013) combine the estimation of a parametric demand system with subjective data on income satisfaction. Their results also suggest that household economies of scale increase in reference income (or in reference utility, respectively).

\footnotetext{
${ }^{5}$ In their data, Bollinger et al. (2012) do not find evidence against this assumption.
} 
The question of estimating equivalence scales is also related to a strand of the literature that, based on collective household models, aims at identifying economies of scale and resource shares of different household members from consumption data, see Browning et al. (2012), Lewbel/Pendakur (2008b), Bargain/Donni (2012), and Dunbar et al. (2013). As described in Browning et al. (2012) and Dunbar et al. (2013), this involves difficult identification problems which are typically addressed by making assumptions that are similar to the independence of base assumption, in particular resource shares and economies of scale are assumed to be independent of total expenditures (Lewbel/Pendakur, 2008, Dunbar et al., 2013, and Bargain/Donni, 2012). Using subjective utility data may be a way to avoid these difficulties (but one has to be willing to make the assumption that utility statements are comparable across persons, see below).

\section{Econometric Model}

The idea of our approach is quite simple. Let $u_{i t}$ denote the income satisfaction of individual $i=1, \ldots, N$ in period $t=1, \ldots, T$. We then assume that there is a relationship between income satisfaction, equivalent income, and possibly other determinants

$$
\begin{aligned}
& u_{i t}=\gamma \log \left(e q_{i t}\left(w_{i t}, \theta\right)\right)+z_{i t}^{\prime} \beta+\alpha_{i}+\varepsilon_{i t} \\
& e q_{i t}\left(w_{i t}, \theta\right)=\operatorname{hhinc}_{i t} / s\left(w_{i t}, \theta\right)
\end{aligned}
$$

where $e q_{i t}\left(w_{i t}, \theta\right)$ is the equivalent income of individual $i$ in period $t, z_{i t}$ are characteristics that may influence income satisfaction in addition to equivalent income, $\alpha_{i}$ are time-invariant determinants of individual income satisfaction, and $\varepsilon_{i t}$ are time-variant idiosyncratic determinants. The equivalent income $e q_{i t}\left(w_{i t}, \theta\right)$ is computed by dividing household income $h h i n c_{i t}$ by an equivalence scale $s\left(w_{i t}, \theta\right)$, which may depend on characteristics $w_{i t}$ and parameters $\theta$. The purpose of the equivalence scale is to make household incomes comparable across households with characteristics $w_{i t}$. Following the literature (e.g., Bellemare et al., 2002, Frijters et al., 2004, Powdthavee, 2010, Sacks et al., 2010), we generally assume that the relationship between income and satisfaction is logarithmic, but we also test for this within a more general isoelastic specification and find the log-specification to be a good choice in most cases (see Layard et al., 2008, and below).

We adopt a first differencing approach in order to eliminate unobserved time-invariant determi- 
nants of income satisfaction $\alpha_{i}$, i.e. we base our estimations on

$$
\Delta u_{i t}=\gamma \Delta \log \left(e q_{i t}\left(w_{i t}, \theta\right)\right)+\Delta z_{i t}^{\prime} \beta+\Delta \varepsilon_{i t}
$$

Note that (1) and (3) are nonlinear regression models because the parameters of the equivalence scale $\theta$ enter the model through $e q_{i t}\left(w_{i t}, \theta\right)$ in a nonlinear way. In $(3)$, the parameters $(\gamma, \beta, \theta)$ can be consistently estimated using nonlinear least squares, if for the error term $\Delta \varepsilon_{i t}$ of the equation, $E\left(\Delta \varepsilon_{i t} \mid \Delta \log \left(e q_{i t}\left(w_{i t}, \theta\right)\right), \Delta z_{i t}\right)=0$ (see Wooldridge (2010), assumption NLS.1). A sufficient condition for this is that $E\left(\varepsilon_{i t} \mid z_{i}, w_{i}\right)=0$ with $z_{i}=\left(z_{i 1}, \ldots, z_{i T}\right)$ and $w_{i}=\left(w_{i 1}, \ldots, w_{i T}\right)$, i.e. the variables $w_{i}$ and $z_{i}$ must be unrelated to the idiosyncratic determinants $\varepsilon_{i t}$ of income satisfaction. Note that the assumption $E\left(\varepsilon_{i t} \mid z_{i}, w_{i}\right)=0$ leaves the relationship between the unobserved time-invariant effects $\alpha_{i}$ and all other components of the model $e q_{i t}\left(w_{i t}, \theta\right), z_{i t}, w_{i t}, \varepsilon_{i t}$ completely unrestricted, i.e. the omitted time-invariant determinants of income satisfaction $\alpha_{i}$ may be arbitrarily correlated with any of the explanatory variables or the idiosyncratic shocks $\varepsilon_{i t}$.

We note that model (1) assumes a cardinal structure of income satisfaction. In our data (see next section), such an assumption is easily defended as our income satisfaction variable uses a scale with eleven points and two clearly defined end points ('totally happy' and 'totally unhappy') such that most respondents will probably intend their answer to this survey question to be a cardinal one. Moreover, Ferrer-i-Carbonell/Frijters (2004) have shown that results using cardinal models generally do not differ in substantial ways from results using ordinal models. We choose a cardinal approach because there is no easy way to take proper account of unobserved characteristics $\alpha_{i}$ in existing multinomial or ordinal models (Wooldridge, 2010). A possible solution to this problem would be to collapse the satisfaction variable into a dichotomous indicator (Winkelmann/Winkelmann, 1998, Schwarze, 2003, Ferrer-i-Carbonell/Frijters, 2004, among others) and to use a fixed effects logit model. This is likely to lead to a considerable drop in efficiency however, especially in our case. Another option would be to use a flexible ordered logit or probit model with random effects (Boes/Winkelmann, 2010), which makes stronger distributional and functional form assumptions. For these reasons, we concentrate on the fixed effects approach described above.

One should also bear in mind that the use of satisfaction data in order to estimate equivalence scales requires the assumption that satisfaction statements are comparable across persons. Of course, the validity of this assumption is open to debate, but given the 'absolute' and 'metric' nature of our scale (it has got two clearly defined endpoints and a fine grid of eleven points with an association of equal distances), it seems plausible that survey respondents attach some absolute 
meaning to their satisfaction statements that corresponds well to how the word 'satisfied' is used in society.

\section{Data}

We use yearly data from the German Socio-Economic Panel (SOEP). Our dependent variable is income satisfaction, i.e. the answer to the survey question 'How satisfied are you with your household income' on a scale from 0 to 10 . By focussing on income satisfaction we sidestep the problem that for more general satisfaction measures (such as satisfaction with life), a very large number of determining factors should be taken into account (for the wide range of these factors see Frey/Stutzer, 2002, Oswald, 2003, Blanchflower/Oswald, 2004a,b). Equivalence scales are about equivalizing the utility assigned to income so that it seems adequate to focus on satisfaction with income rather than on more general satisfaction measures. ${ }^{6}$

Our income measure is monthly net household income as reported by the household head at survey time. As potential further covariates of income satisfaction we originally considered a large number of individual and household characteristics as well as individual or household events. We excluded variables that did not or that changed only little over time (education, region etc.) as those are automatically controlled for in our first-differencing procedure. The list of variables originally considered by us included age, age squared, the number of days spent ill in the previous year, the number of months spent on unemployment benefits or social assistance in the previous year, the degree of disability, as well as dummies indicating whether the person was unemployed at survey time, whether there were other unemployed persons in the household, whether the person worked part time, whether the person was married, whether the person was married but separated, in education, retired or out of the labor force. In order to account for possible relative effects of income satisfaction, we included quartile dummies describing the relative position of the household in the overall distribution of household incomes. ${ }^{7}$

We also considered a number of events such as whether the person was newly married, soon

\footnotetext{
${ }^{6} \mathrm{~A}$ related view is that overall satisfaction can be decomposed into different 'domains', see Easterlin/Sawangfa (2007). We also experimented with using general life satisfaction as the dependent variable but found it hard to obtain statistically significant results.

${ }^{7}$ We generally found these dummies to be highly significant (see below). Omitting them did not change the estimates of the equivalence scale parameters much, but they tended to be slightly lower if the quartile dummies were not included.
} 
to be married, newly divorced, soon to be divorced, whether somebody in the household had died, whether a child recently left the household, whether there was a new born baby in the household, or whether the person had recently become disabled. In general, we excluded all variables whose share of nonzero changes over a period of five years was below three percent. This applied to almost all of the events considered and to many of the other potential covariates listed above (see results below). We also omitted in our final specifications covariates that were grossly insignificant. In general, we found that the estimates of our equivalence scale parameters did not depend much on whether we omitted certain covariates from our regressions. We also included a full set of time dummies (implying that we omitted age but kept age squared as a regressor). In order to test whether dynamic effects of income matter, we also tried out adding the change in equivalent income $\Delta e q_{i t}$ as a regressor in (1) (i.e. we included $\Delta\left(\Delta e q_{i t}\right)$ in (3)). This generally yielded a statistically insignificant coefficient and did not change any of our other results so that we did not include $\Delta e q_{i t}$ in our final specification (similar findings were reported in Layard et al., 2008).

Our sample consists of all individuals with non-missing information on the variables described above. This excludes individuals under 16 years of age as SOEP questionnaires are only addressed to individuals aged 16 years or older. Our overall sample period comprises the years 1999 to 2009 . We look at the three subperiods 1999 to 2003, 2002 to 2006, and 2005 to 2009, i.e. we estimate (3) for each of these subperiods. In order to minimize the influence of outliers, we drop the top percentile of income observations. We also take account of the clustering of individuals in households and over time by computing clustered standard errors based on the original household identifier of the survey. This means we cluster together individuals who either live together in a given period or who are otherwise related because their households are the result of a household split in earlier periods. This allows for arbitrary correlation within household clusters as well as for heteroscedasticity over time (Wooldridge, 2010).

\section{Empirical Results}

\subsection{Estimating and evaluating standard scales}

In this section, we apply the framework described above to estimate and evaluate three commonly used scales, the Luxembourg (or square-root) scale, the (modified) OECD scale, and the 
Banks/Johnson-scale (see Atkinson et al., 1995, OECD, 2005, and Banks/Johnson, 1994).

Luxembourg scale

The Luxembourg scale is a special case of the parametric form

$$
s\left(\text { hhsize }_{i t}, \alpha\right)=\left(\text { hhsize }_{i t}\right)^{\alpha},
$$

where in the specific case of the Luxembourg scale, the economies of scale parameter $\alpha$ is set to one half. We estimate (4) by treating $\alpha$ as a free parameter using the procedure described above. The estimation results for $\alpha$ are shown in the first column of table 1 . Selected results for other regression parameters are given in the appendix (this is also true for all other specifications reported below).

\section{- Table 1 around here -}

The estimates for the economies of scale parameter are between .28 and .34 and are statistically significantly different from one half. The results for $\alpha$ are very similar to the estimates in Schwarze (2003) who also uses SOEP data but who applies the technique of collapsing income satisfaction into a dichotomous indicator. Note that the economies of scale suggested by these estimates is much lower than those implied by the Luxembourg scale with $\alpha=.5$.

OECD scale

Next we estimate the scale

$$
s\left(\text { hhsize }_{i t}, \text { children }_{i t}, a, b\right)=1+a \cdot\left(\text { hhsize }_{i t}-\text { children }_{i t}-1\right)+b \cdot \text { children }_{i t},
$$

where children $_{i t}$ the number of household members aged 14 years or younger and hhsize $e_{i t}$ the household size as before. The OECD equivalence scale results as a special case with $a=.5$ and $b=.3$, i.e. the first person in the household receives a weight of one, each additional adult ${ }^{8}$ a weight of .5 and an additional child receives a weight of .3 (an older choice was $a=.7, b=.5$, see Atkinson et al., 1995). The estimates for $a$ and $b$ using the method described above are shown in the second and third column of table 1 . The weight for an additional adult is estimated at around .17 to .22 , that of an additional child at around .08 to .11 The hypothesis of $a=.5$

\footnotetext{
${ }^{8}$ In accordance with the language use associated with the OECD scale, we call household members aged 15 or older 'adults'.
} 
and $b=.3$ (and that of $a=.7, b=.5$ ) is clearly rejected. There also seems to be the tendency that the estimated weight for an adult is about twice as large as that of a child.

As an illustration that our estimated equivalence scale parameters really reflect underlying structures in income satisfaction, we decompose the nonlinear least squares problem (3) in two steps. We first estimate for given $a, b$ linear regressions of $\Delta u_{i t}$ on $\Delta e q_{i t}(a, b)$ and $\Delta z_{i t}$ over a grid of values for $a$ and $b$. Among the regressions for all the grid points, we then choose the regression that has the best fit. Figure 1 presents the contour plot of the R-squared of such regressions over the grid of $a$ and $b$. One can see that the objective function with respect to the parameters of the equivalence scale $a$ and $b$ is very well-behaved with a unique optimum at the values that result from the nonlinear least squares procedure.

- Figure 1 around here -

\section{Banks/Johnson scale}

Another popular choice for a parametrized equivalence was suggested by Banks/Johnson (1994). The scale is defined by

$$
s\left(\text { adults }_{i t}, \text { children }_{i t}, a, b\right)=\left(\text { adults }_{i t}+\eta \cdot \text { children }_{i t}\right)^{\alpha},
$$

i.e. children receive a weight $\eta$ when compared to adults, and the economies of scale parameter is given by $\alpha$ as in the case of the Luxembourg scale. The estimation results for this scale are shown in the last two columns of table 1. The estimated weight for children is between .4 and .6 , suggesting, as before, that the weight of a child is about half that of an adult. The estimated economies of scale parameter is very similar to that of the Luxembourg scale. Again, we clearly reject the hypothesis that $\alpha=.5$.

More detailed regression results for the three specifications are given in table 9. The estimation results for other regressors are in line with prior expectations. Interestingly, the estimated coefficients for the other regressors are practically invariant across the three specifications. The fit of the different specifications as measured by the sum of squared residuals suggests that the Banks/Johnson-scale has a slight advantage over the other two specifications. ${ }^{9}$

\footnotetext{
${ }^{9}$ It might make sense to correct for the degrees of freedom (i.e. divide by the number of observations minus the number of estimated parameters). Given the large number of observations however, this makes little difference.
} 


\subsection{Iso-elastic specification}

As indicated above, we check the robustness of our results with respect to the assumption that the relationship between income satisfaction and equivalent income is a logarithmic one by nesting the log-specification in the more general iso-elastic specification (Layard et al., 2008). Equations (1) and (3) then change to

$$
\begin{aligned}
& u_{i t}=\gamma \cdot \frac{e q_{i t}\left(w_{i t}, \theta\right)^{\lambda}-1}{\lambda}+z_{i t}^{\prime} \beta+\alpha_{i}+\varepsilon_{i t} \\
& \Delta u_{i t}=\gamma \cdot \Delta\left[\frac{e q_{i t}\left(w_{i t}, \theta\right)^{\lambda}-1}{\lambda}\right]+\Delta z_{i t}^{\prime} \beta+\Delta \varepsilon_{i t} .
\end{aligned}
$$

The iso-elastic specification assumes that marginal income satisfaction with respect to income is constant and equal to $1-\lambda$. The special case of the log-specification results for $\lambda \rightarrow 0$.

\section{- Table 2 around here -}

The results for the Luxembourg scale and the OECD scale using the iso-elastic assumption are reported in table 2 (more detailed results are given in table 10 in the appendix). In two of the cases, the estimate for $\lambda$ is slightly below zero, but not statistically significant. For the period 2005 to 2009 , the estimate is more negative and statistically significant. Note however, that the estimates of the equivalence scale parameters are very similar to those obtained in the log-specification so that it seems insubstantial in the given context whether or not the log-specification or the more general iso-elastic specification is chosen.

\subsection{Details of the household structure}

Next, we investigate the role of further household characteristics.

Age of children

We extend the OECD-type scale in order to allow for children of different ages. More specifically, we estimate

$$
\begin{aligned}
& \text { s(hhsize } \text { it }_{\text {children } \left.05_{i t}, \text { children } 613_{i t}, a, b_{1}, b_{2}\right)} \\
& =1+a \cdot\left(\text { hhsize } i t-\text { children } 613_{i t}-{\text { children } \left.05_{i t}-1\right)}\right. \\
& \quad+b_{1} \cdot \text { children } 613_{i t}+b_{2} \cdot \text { children } 05_{i t},
\end{aligned}
$$


where children $05_{i t}$ is the number of children aged at most five years, children $613_{i t}$ the number of children aged between 6 and 13 years. The results are shown in table 3 (and in table 11 in the appendix). They indicate that the weight for younger children is indeed slightly lower than the weight for older children but the difference is far from being significant. We conjecture that much larger sample sizes would be required to trace out differences in equivalence weights for children of different ages.

— Table 3 around here -

The role of partners in the household

Following Bollinger et al. (2012), we distinguish between household members who are in a partner relationship and household members who are not. More specifically, we estimate

$$
\begin{aligned}
& \text { shhize } \left._{i t}, \text { partner }_{i t}, \text { children }_{i t}, a_{1}, a_{2}, b\right) \\
& =1+a_{1} \cdot \text { partner }_{i t}+a_{2} \cdot\left(\text { hhsize }_{i t}-\text { partner }_{i t}-\text { children }_{i t}-1\right) \\
& \quad+b \cdot \text { children }_{i t}
\end{aligned}
$$

where partner $_{i t}$ is the number of household members who are the partner of another household member, divided by two (in order to avoid double counting). The results are shown in table 4 (and in table 11 in the appendix). The weight of an additional adult who is a partner of another household member is estimated to be very low and statistically insignificant for the periods 1999 to 2003 and 2002 to 2006. This is similar to the results in Bollinger et al. (2012) for British data. However, for the period 2005 to 2009, the weight of a parter is estimated higher and statistically different from zero, although still lower than the weight of a non-partner.

$$
\text { - Table } 4 \text { around here - }
$$

\subsection{Income dependency}

In this section, we use different functional forms in order to test the 'Independence of Base Assumption' (Lewbel, 1989, Blackorby/Donaldson, 1993), i.e. we investigate to what extent the equivalence scale and its economies of scale depend on reference income. Our framework allows 
us to carry out such a test as we just have to relate the equivalence scale parameters to the level of equivalent income. ${ }^{10}$

\section{Direct estimation Luxembourg scale}

In the case of the Luxembourg-type scale

$$
s\left(\text { hhsize }_{i t}, \alpha\right)=\left(\text { hhsize }_{i t}\right)^{\alpha},
$$

assume that the economies of scale parameter $\alpha$ is related to equivalent income as

$$
\alpha=\alpha_{1}+\alpha_{2}\left[\log \left(e q_{i t}\left(h_{h s i z e} e_{i t}, \alpha\right)\right)-\log \left(q^{*}\right)\right]
$$

where $q^{*}$ is some fixed income level. If $\alpha_{2} \neq 0$, then the economies of scale $\alpha$ depend either positively or negatively on the level of reference income (= equivalent income). The parameter $\alpha_{1}$ represents the economies of scale for a particular fixed level of equivalent income $q^{*}{ }^{11}$ Combining

$$
\log \left(e q_{i t}\left(\text { hhsize }_{i t}, \alpha\right)\right)=\log \left(\text { hhinc }_{i t}\right)-\alpha \log \left(\text { hhsize }_{i t}\right)
$$

with (13) and solving for $\log \left(e q_{i t}\left(h h s i z e_{i t}, \alpha\right)\right)$ yields

$$
\log \left(\text { eq }_{i t}\left(\text { hhsize }_{i t}, \alpha\right)\right)=\frac{\log \left(\text { hhinc }_{i t}\right)-\alpha_{1} \log \left(\text { hhsize }_{i t}\right)-\alpha_{2} \log \left(q^{*}\right) \log \left(\text { hhsize }_{i t}\right)}{1+\alpha_{2} \log \left(\text { hhsize }_{i t}\right)},
$$

which we insert in first differenced form in (3) in order to estimate $\alpha_{1}, \alpha_{2}$.

The resulting estimates for $\alpha_{1}$ and $\alpha_{2}$ are shown in the first two columns of table 5 (and in table 12 in the appendix). For the period 1999 to 2003, the results suggest that economies of scale rise with equivalent income in a statistically significant way. For 2002 to 2006 and for 2005 to 2009 , the dependency on equivalent income is weaker and only marginally significant. The result for 1999 to 2003 suggests that a ten percent increase in equivalent income is associated with an increase of the economies of scale parameter $\alpha$ of around .0336 because

$$
\alpha_{2}=.336=\frac{\partial \alpha}{\partial \log \left(e q_{i t}\right)}=\frac{\partial \alpha}{\frac{\partial e q_{i t}}{e q_{i t}}}=\frac{.0336}{\frac{10}{100}}=\frac{.0336}{10 \%} .
$$

This is a small but discernible effect.

\footnotetext{
${ }^{10}$ Unfortunately, there seems to be no easy way to test more general restrictions such as 'Generalized Equivalence Exactness' (GESE, Donaldson/Pendakur, 2003).

${ }^{11}$ This could be any income level of interest, for example 1000 Euros or 2000 Euros. Below, we will set $q^{*}$ to the pooled median of equivalized incomes in the respective 5-year window.
} 
Iterative estimation Luxembourg scale

Specifying the relationship between the economies of scale parameter $\alpha$ and the equivalent income as logarithmic, we were able to obtain a closed form expression for $\log \left(e q_{i t}\right)$, which we could insert in our estimation equation. For other specifications, this is not possible. If we assume equivalence scale parameters to be dependent on equivalent income, we face the problem that equivalent income in turn depends on the equivalence scale parameters. In order to solve that problem, we pursue an iterative approach.

We first apply this to a linear (rather than log-linear) specification of the relationship between the economies of scale parameter of the Luxembourg scale

$$
\alpha=\alpha_{1}+\alpha_{2}\left[\frac{e q_{i t}\left(\text { hhsize }_{i t}, \alpha\right)}{1000}-\frac{q^{*}}{1000}\right] .
$$

Again, $\alpha_{1}$ is the economies of scale parameter for an equivalent income of $q^{*}$ and $\alpha_{2}$ describes by what amount the economies of scale parameter $\alpha$ changes if equivalent income changes by 1000 Euros. In order to estimate $\alpha_{1}$ and $\alpha_{2}$, we use the following iterative procedure. We start with initial values $\alpha_{1}^{0}$ and $\alpha_{2}^{0}$ for $\alpha_{1}$ and $\alpha_{2}$ and use these initial values to compute for each individual their equivalent income $e q_{i t}\left(h h s i z e_{i t}, \alpha_{1}^{0}, \alpha_{2}^{0}\right)$. Using this equivalent income, we carry out the nonlinear least squares estimation procedure to obtain new estimates $\alpha_{1}^{1}$ and $\alpha_{2}^{1}$. We use these new values for $\alpha_{1}$ and $\alpha_{2}$ to compute a new estimate of $e q_{i t}\left(h h s i z e_{i t}, \alpha_{1}^{1}, \alpha_{2}^{1}\right)$ for each individual, which we insert in another round of nonlinear least squares estimation to obtain new estimates $\alpha_{1}^{2}$ and $\alpha_{2}^{2}$, and so on. Doing this, our estimates for $\alpha_{1}$ and $\alpha_{2}$ converge very quickly to values that we report in the last two columns of table 5.

The resulting estimates for $\alpha_{1}$ are very similar to the ones of the log-linear specification and correspond well to the general estimate for the economies of scale parameter of the Luxembourg scale in the case without income dependency. The estimates for $\alpha_{2}$ are also positive, suggesting a negative relationship between economies of scale and equivalent income as before. As in the log-linear case, we also observe a falling tendency of the income dependency parameter, but this time, they are statistically significant for all years. ${ }^{12}$ Taking the estimate for the period 2002 to

\footnotetext{
${ }^{12}$ Note that, due to the iterative procedure, the standard errors are only approximate. Given their very small size and the fact that they practically do not differ from those of a one-step estimate, it seems unlikely that any correction would change the finding that $\alpha_{2}$ is significantly different from zero.
} 
2006, we obtain the result that the economies of scale parameter $\alpha$ grows by .077 if the equivalent income increases by 1000 Euros. Again, this is a small but discernible effect.

\section{Iterative estimation OECD scale}

We apply the same idea to the OECD-type scale in which we make the weights for adults and for children dependent on equivalent income, i.e.

$$
\begin{aligned}
& a=a_{1}+a_{2}\left[\frac{e q_{i t}\left(\text { hhsize }_{i t}, \text { children }_{i t}, a, b\right)}{1000}-\frac{q^{*}}{1000}\right] \\
& b=b_{1}+b_{2}\left[\frac{e q_{i t}\left(\text { hhsize }_{i t}, \text { children }_{i t}, a, b\right)}{1000}-\frac{q^{*}}{1000}\right] .
\end{aligned}
$$

The results are reported in table 6. Again, we generally observe that the weight for additional household members increases with rising equivalent income, i.e. the economies of scale are falling in income. However, this is only true for adults. For children, there is the opposite effect, i.e. the weight of an additional child decreases with income. ${ }^{13}$

\section{- Table 6 around here -}

How can these patterns be explained? For additional adults, we find that economies of scale are falling in income. A possible reason is that the budget share of goods that exhibit particularly high economies of scale (housing, cars, household appliances etc.) tend to be falling in income. Another reason could be that the consumption behavior of richer households may be characterized to a larger extent by individualized consumption patterns (everyone has their own room, car etc.) which, by definition, results in a lower degree of sharing. To put it differently, poorer households may feel a stronger necessity to spend their income on sharable goods in order to reach a decent standard of living. On the other hand, we find the reverse result of rising economies of scale for children. A possible explanation is that a larger number of children (i.e. two or three children instead of just one) usually goes hand in hand with a more family oriented way of living in which family activities (going on holiday together, eating out in expensive restaurants etc.) play a larger role. Richer households may be in a better situation to finance such common activities. As the results in table 7 show, the combined effect of adults and children lead to economies of scale that are rising in income for households with two or more children.

\footnotetext{
${ }^{13} \mathrm{We}$ also tried including in (18) an interaction term between the term in brackets and the number of children, but this interaction term was very insignificant.
} 
Our result that economies of scale may be decreasing (rather than increasing or being constant) in income for childless households is in contrast to some results in the literature (Donaldson/Pendakur, 2003, Koulovatianos et al., 2005, De Ree et al., 2013). For example, by directly asking respondents how they think equivalence scales should vary with income, Koulovatianos et al. (2005) find that economies of scale are larger for higher incomes. The results in Donaldson/Pendakur (2003) based on the full estimation of a consumer demand system suggest rising economies of scale for households with children and constant (or slightly rising) economies of scale for childless households. These latter results are not so different from ours, especially in that households with children experience rising economies of scale (also see table 7 and the discussion below). Using data for Indonesia and not distinguishing between adults and children, De Ree et al. (2013) also find that economies of scale rise with reference income. Overall, there are huge methodological and data differences between our study and these contributions so that it is hard to assess why results differ. All we can say is that our results represent an additional piece of evidence about the possible income dependency of equivalence scales which may be of particular interest as it is based on direct satisfaction statements without reference to consumption data or assumptions such as utility maximization.

\subsection{Consequences for inequality and poverty}

Table 7 lists the resulting equivalence scales for different household types. As already discussed above, there are considerable differences between the official Luxembourg and OECD scales and their estimated counterparts. The estimated Banks/Johnson scale is very similar to the estimated OECD scale, which is remarkable given their very different structure. The results for the scale with a special role for partners (averaged over all households in the sample), reflect the fact that a second adult in the household is often a partner, while a third one is one who is not a partner of another household member. This results in a discernible jump in the scale between the second and the third adult, while the addition of a second adult is mostly associated with only a small increase in weight. Finally, the last nine rows of table 7 demonstrate how economies of scale vary with income. The results for the linear and log-linear specification of the Luxembourg scale are very similar, which is reassuring as it shows that our estimates are robust with respect to functional form specification. The last three rows of table 7 show the results where the incomedependency of the scale may vary between adults and children. It can be seen that this generally results in rising economies of scale for households with up to one child, but falling economies of 
scale for households with two ore more children. Note that this to a certain extent reconciles our results with those in Donaldson/Pendakur (2003) for Canada who also find that equivalence scales for household with children significantly fall in income.

\section{- Table 7 around here -}

In table 8, we investigate how estimates of standard inequality and poverty measures are changed if we use our estimated scales instead of the OECD or Luxembourg scale. The shift in mean and median equivalized income shown in the first two columns of the table reflects the general differences in economies of scale across the different scales. Economies of scale are higher for the estimated scales than for the standard OECD and Luxembourg scales, leading to considerably higher values for mean and median equivalized income. As discussed above, economies of scale are particularly high for the scale incorporating the effect of partners living in the household. The last two columns show the effect on the Gini coefficient, the mean logarithmic deviation, and the Theil coefficient. It turns out that the differences in estimated inequality levels between the standard scales (see the first two rows of table 8) and their estimated counterparts are surprisingly small (rows three to five). The differences are much larger however, if we compare the standard scales to the income dependent scales (last three rows in table 8). In the case of the income dependent scales, inequality is considerably lower. The obvious reason for this is that in our results, economies of scale generally decrease in income so that poorer households benefit more from them than richer ones, narrowing the gap between the lower and the upper part of the distribution. We do find increasing economies of scale for households with two or more children, but these households represent only a minority of the population.

\section{- Table 8 around here -}

The second column table 8 shows the results for the poverty rate. We set the poverty line to the conventional value of 60 percent of the median. As this is a relative definition of poverty, a shift in household economies of scale has two different effects: one on the poverty line (via the median), and one on the position of households in the population. It is therefore not surprising that the estimated standard scales (rows three to five in table 8) which imply higher economies of scale than the official versions (rows one and two) increase the measured poverty rate as they mainly lift the poverty line upwards (via a higher median). In the case of the income dependent scales, the positional effect on households dominates, i.e. low income households generally benefit more 
from household economies of scale than richer ones, leading to a lower fraction of households below the poverty line.

\section{Conclusion}

In this paper, we explore a new way to use income satisfaction data in order to estimate equivalence scales. Our approach differs from previous attempts to use satisfaction data for this purpose in that it directly considers the relationship between income satisfaction and the correctly equivalized household income. Our method makes it easy to test commonly used parametric forms of equivalence scales and to investigate specific properties such as the dependence of the scale on reference income or on further household characteristics. Our implementation using data from the German Socio-Economic Panel suggests that household economies of scale are higher than those in commonly used scales such as the OECD or the Luxembourg scale. We also confirm the hypothesis put forward by Bollinger et al. (2012) that economies of scale are particularly high if some of the household members are in a partner relationship. Finally, we obtain the novel empirical result that household economies of scale may decrease (rather than increase or be constant) in income. We also investigate the consequences of using our method on measures of poverty and inequality. These seem to be relatively limited in the case of income independent equivalence scales but substantial if equivalence scales may depend on income. 


\section{Literature}

Atkinson, A.B., L. Rainwater, and T.M. Smeeding (1995): Income Distribution in OECD Countries, OECD Social Policy Studies, No. 18, Paris.

Banks, J., P. Johnson (1994): Equivalence Scale Relativities Revisited, Economic Journal, Vol. $104,883-890$.

Bargain, O., O. Donni (2012): Expenditure on Children: A Rothbarth-Type Method Consistent with Scale Economies and Parents, European Economic Review, Vol. 56 (4), 792-813.

Bellemare, C., B. Melenberg and A. van Soest (2002): Semi-parametric models for satisfaction with income, Portuguese Economic Journal, Vol. 1, 181-203.

Blackorby, C, D. Donaldson (1993): Adult-equivalence scales and the economic implementation of interpersonal comparisons of well-being, Social Choice and Welfare, Vol. 10, 335-361.

Blanchflower, D., A. Oswald (2004a): Well-Being Over Time in Britain and the USA, Journal of Public Economics, Vol. 88, 1359-1386.

Blanchflower, D., A. Oswald (2004b): Money, Sex, and Happiness: An Empirical Study, Scandinavian Journal of Economics, Vol. 106, 393-416.

Blundell, R., Lewbel, A. (1991): The information content of equivalence scales, Journal of Econometrics, Vol. 50, 49-68.

Blundell, R., A. Duncan, K. Pendakur (1998): Semiparametric estimation of consumer demand, Journal of Applied Econometrics, Vol. 13, 435-461.

Boes, S., R. Winkelmann (2010): The Effect of Income on General Satisfaction and Dissatisfaction, Social Indicators Research, Vol. 25, 111-128.

Bollinger, C.R., C. Nicoletti, and S. Pudney (2012): Two can live as cheaply as one ... but three is a crowd, ISER Discussion Paper No. 2012-10, Institute for Social and Economic Research, University of Essex.

Browning, M., P.A. Chiappori, A. Lewbel (2012): Estimating Consumption Economies of Scale, Adult Equivalence Scales, and Household Bargaining Power, Working Paper, Boston College.

De Ree, J., R. Alessi, M. Pradhan (2013): The price and utility dependence of equivalence scales: 
Evidence from Indonesia, Journal of Public Economics, Vol. 97, 272-281.

Dickens, R., V. Fry, P. Pashardes (1993): Nonlinearities, aggregation and equivalence scales, Economic Journal, Vol. 103, 359-368.

Donaldson, D., K. Pendakur (2003): Equivalent-Expenditure Functions and ExpenditureDependent Equivalence Scales, Journal of Public Economics, Vol. 88, 175-208.

Donaldson, D., K. Pendakur (2006): The Identification of Fixed Costs From Consumer Behaviour, Journal of Business and Economic Statistics, Vol. 24, 255-265.

Dunbar, G., A. Lewbel, K. Pendakur (2013): Children's Resources in Collective Households: Identification, Estimation and an Application to Child Poverty in Malawi, forthcoming American Economic Review

Easterlin, R.A., W. Sawangfa (2007): Happiness and Domain Satisfaction, Theory and Evidence, IZA Discussion Paper No. 2584, Institute for the Study of Labor, Bonn.

Ferrer-i-Carbonell, A., P. Frijters (2004): How Important Is Methodology for the Estimates of the Determinants of Happiness?, Economic Journal, Vol. 114, 641-59.

Frey, B.S., A. Stutzer (2002): Happiness and Economics: How the Economy and Institutions Affect Human Wellbeing, Princeton University Press.

Frijters, P., J.P. Haisken-DeNew, and M.A. Shields (2004): Money does matter! Evidence from increasing real income and life satisfaction in East Germany following reunification, American Economic Review, Vol. 94, 730-740.

Juhasz, A. (2012): A Satisfaction-Driven Poverty Line - A Bustle around the Poverty Line, SOEPpaper No. 461, DIW Berlin.

Kapteyn, A., B. van Praag (1976): A New Approach to the Construction of Family Equivalence Scales, European Economic Review, Vol. 7, 313-335.

Koulovatianos, C., U. Schmidt, and C. Schröder (2005): On the Income Dependence of Equivalence Scales, Journal of Public Economics, Vol. 89, 967-996.

Layard, R., G. Mayraz, and S. Nickell (2008): The marginal utility of income, Journal of Public Economics, Vol. 92, 1846-1857. 
Lewbel, A. (1989): Household Equivalence Scales and Welfare Comparisons, Journal of Public Economics, Vol. 39, 377-391.

Lewbel, A., K. Pendakur (2008a): Equivalence Scales, in: Durlauf, S., L. Blume, The New Palgrave Dictionary of Economics, 2nd Edition, Palgrave Macmillan.

Lewbel, A., K. Pendakur (2008b): Estimation of Collective Household Models with Engel Curves, Journal of Econometrics, Vol. 147, 350-358.

Melenberg, C., A. van Soest (1996): Semiparametric estimation of equivalence scales using subjective information, in Nyhus, E, S.V. Troye (eds.), Frontiers in Economic Psychology - 20th IAREP conference, IAREP, Bergen, 500-514.

Muellbauer, J. (1980): The Estimation of the Prais-Houthakker Model of Equivalence Scales, Econometrica, Vol. 48, 153-176.

OECD (2005): What are equivalence scales?, available at www.oecd.org/dataoecd/61/52/35411111.pdf.

Oswald, A. (2003): How Much do External Factors Affect Wellbeing? A Way to Use 'Happiness Economics' to Decide", The Psychologist, Vol. 16, 140-141.

Pashardes, P. (1995): Equivalence Scales in a Rank-3 Demand System, Journal of Public Economics, Vol. 58, 143-158.

Pendakur, K. (1999): Estimates and tests of base-independent equivalence scales, Journal of Econometrics, Vol. 88, 1-40.

Sacks, D.W., B. Stevenson, J. Wolfers (2010): Subjective Well-Being, Economic Development and Growth, NBER Working Paper, No. 16441, National Bureau of Economic Research.

Schröder, C. (2009): The Construction and Estimation of Equivalence Scales and Their Uses, in: Slottje, D. (Ed.), Quantifying Consumer Preferences, Contributions to Economic Analysis, 288, Emerald, Bingley.

Schwarze, J. (2003): Using Panel Data on Income Satisfaction to estimate Equivalence Scale Elasticity, Review of Income and Wealth, Vol. 3, 359-372.

van Praag, B. (1968): Individual welfare functions and consumer behavior, North- Holland, Amsterdam. 
van Praag, B. (1991): Ordinal and Cardinal Utility: an integration of the two dimensions of the welfare concept, Journal of Econometrics, Vol. 50, 69-89.

van Praag, B., N.L. van der Sar (1988): Household cost functions and equivalence scales, Journal of Human Resources, Vol. 23, 193-210.

Winkelmann, L. and Winkelmann, R. (1998): Why are the unemployed so unhappy? Evidence from panel data, Economica, Vol. 65, 1-15

Wooldridge, J.M. (2010):Econometric Analysis of Cross-Section and Panel Data, 2nd edition, MIT Press, Cambridge. 


\section{Figures}

Figure 1 - Illustration of objective function for OECD scale

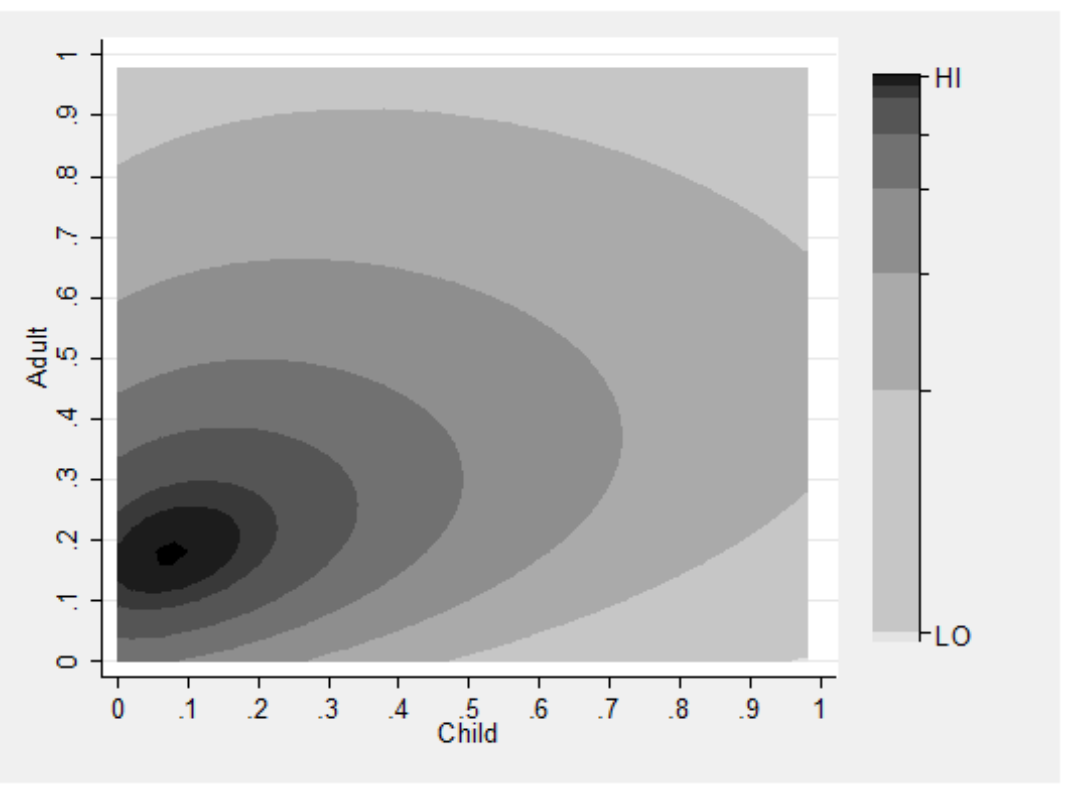

Source: SOEP, own calculations. The figure shows the contour plot of the R-squared of first-differenced regressions carried out over a grid of values for the parameters of the OECD scale $a$ (= adult weight) and $b$ (= children weight). 


\section{Tables}

Table 1 - Results for standard scales

\begin{tabular}{|l|cc|cc|cc|cc|cc|}
\hline & Luxembourg & \multicolumn{4}{|c|}{ OECD } & \multicolumn{4}{c|}{ Banks/Johnson } \\
\hline & \multicolumn{2}{|c|}{$\alpha$} & $a$ (adult) & $b$ (children) & $\eta$ (children) & \multicolumn{2}{c|}{$\alpha$} \\
\hline $1999-03$ & .321 & $(.052)$ & .198 & $(.040)$ & .107 & $(.044)$ & .622 & $(.274)$ & .341 & $(.055)$ \\
$2002-06$ & .341 & $(.055)$ & .218 & $(.043)$ & .102 & $(.048)$ & .510 & $(.251)$ & .364 & $(.057)$ \\
$2005-09$ & .281 & $(.049)$ & .165 & $(.035)$ & .076 & $(.042)$ & .408 & $(.266)$ & .305 & $(.051)$ \\
\hline
\end{tabular}

Source: SOEP, own calculations. Standard errors account for

longitudinal sample design and household clustering.

Table 2 - Results for Luxembourg and OECD scale using iso-elastic specification

\begin{tabular}{|l|cc|cc|cc|cc|cc|}
\hline & \multicolumn{4}{|c|}{ Luxembourg } & \multicolumn{5}{c|}{ OECD } \\
\hline & \multicolumn{2}{|c|}{$\alpha$} & \multicolumn{2}{|c|}{$\lambda$} & \multicolumn{2}{c|}{$a$ (adult) } & $b$ (children) & \multicolumn{2}{c|}{$\lambda$} \\
\hline $1999-03$ & .304 & $(.053)$ & -.117 & $(.105)$ & .182 & $(.040)$ & .117 & $(.045)$ & -.112 & $(.103)$ \\
$2002-06$ & .332 & $(.056)$ & -.124 & $(.104)$ & .208 & $(.043)$ & .122 & $(.051)$ & -.115 & $(.101)$ \\
$2005-09$ & .277 & $(.051)$ & -.263 & $(.067)$ & .151 & $(.037)$ & .119 & $(.050)$ & -.253 & $(.067)$ \\
\hline
\end{tabular}

Source: SOEP, own calculations. Standard errors account for

longitudinal sample design and household clustering.

Table 3 - Details of household structure: age of children

\begin{tabular}{|l|cc|cc|cc|}
\hline & \multicolumn{2}{|c|}{$a$ (adult) } & \multicolumn{2}{c|}{$b_{1}$ (6-13y.) } & \multicolumn{2}{c|}{$b_{2}$ (0-5y.) } \\
\hline 1999-03 & .201 & $(.041)$ & .125 & $(.051)$ & .080 & $(.050)$ \\
2002-06 & .221 & $(.044)$ & .116 & $(.055)$ & .081 & $(.057)$ \\
$2005-09$ & .171 & $(.036)$ & .100 & $(.048)$ & .039 & $(.049)$ \\
\hline
\end{tabular}

Source: SOEP, own calculations. Standard errors account for longitudinal sample design and household clustering. 
Table 4 - Details of household structure: role of partners

\begin{tabular}{|l|cc|cc|cc|}
\hline & \multicolumn{2}{|c|}{$a_{1}$ (part.) } & \multicolumn{2}{|c|}{$a_{2}$ (oth. ad.) } & \multicolumn{2}{c|}{$b$ (children) } \\
\hline $1999-03$ & .053 & $(.057)$ & .241 & $(.034)$ & .125 & $(.042)$ \\
$2002-06$ & .083 & $(.065)$ & .259 & $(.046)$ & .127 & $(.048)$ \\
$2005-09$ & .145 & $(.061)$ & .170 & $(.037)$ & .079 & $(.042)$ \\
\hline
\end{tabular}

Source: SOEP, own calculations. Standard errors account for longitudinal sample design and household clustering.

Table 5 - Income dependency of Luxembourg scale

\begin{tabular}{|l|rr|rr|rr|rr|}
\hline & \multicolumn{3}{|c|}{ log-linear } & \multicolumn{4}{c|}{ linear } \\
\hline & \multicolumn{2}{|c|}{$\alpha_{1}$} & \multicolumn{2}{c|}{$\alpha_{2}$} & \multicolumn{2}{|c|}{$\alpha_{1}$} & \multicolumn{2}{c|}{$\alpha_{2}$} \\
\hline $1999-03$ & .306 & $(.063)$ & .336 & $(.102)$ & .322 & $(.044)$ & .101 & $(.016)$ \\
$2002-06$ & .329 & $(.061)$ & .156 & $(.088)$ & .332 & $(.048)$ & .077 & $(.014)$ \\
$2005-09$ & .277 & $(.053)$ & .127 & $(.080)$ & .273 & $(.043)$ & .069 & $(.015)$ \\
\hline
\end{tabular}

Source: SOEP, own calculations. Standard errors account for

longitudinal sample design and household clustering.

Table 6 - Income dependency of OECD scale

\begin{tabular}{|l|rr|rr|rr|rr|}
\hline & \multicolumn{2}{|c|}{$a_{1}$} & \multicolumn{2}{|c|}{$a_{2}$} & \multicolumn{2}{|c|}{$b_{1}$} & \multicolumn{2}{c|}{$b_{2}$} \\
\hline $1999-03$ & .204 & $(.034)$ & .136 & $(.023)$ & .125 & $(.038)$ & -.040 & $(.015)$ \\
$2002-06$ & .215 & $(.037)$ & .128 & $(.024)$ & .132 & $(.044)$ & -.071 & $(.027)$ \\
$2005-09$ & .155 & $(.030)$ & .104 & $(.018)$ & .109 & $(.040)$ & -.042 & $(.014)$ \\
\hline
\end{tabular}

Source: SOEP, own calculations. Standard errors account for

longitudinal sample design and household clustering. 
Table 7 - Equivalence scales (based on estimates for 2002 to 2006)

\begin{tabular}{|c|c|c|c|c|c|c|c|c|c|c|c|c|}
\hline Equiv. scale & $\mathrm{A} 1 \mathrm{C} 0$ & $\mathrm{~A} 2 \mathrm{CO}$ & $\mathrm{A} 3 \mathrm{CO}$ & $\mathrm{A} 1 \mathrm{C} 1$ & $\mathrm{~A} 2 \mathrm{C} 1$ & $\mathrm{~A} 3 \mathrm{C} 1$ & $\mathrm{~A} 1 \mathrm{C} 2$ & $\mathrm{~A} 2 \mathrm{C} 2$ & $\mathrm{~A} 3 \mathrm{C} 2$ & $\mathrm{~A} 1 \mathrm{C} 3$ & $\mathrm{~A} 2 \mathrm{C} 3$ & $\mathrm{~A} 3 \mathrm{C} 3$ \\
\hline Luxembourg & 1 & 1.41 & 1.73 & 1.41 & 1.73 & 2 & 1.73 & 2 & 2.24 & 2 & 2.24 & 2.45 \\
\hline OECD & 1 & 1.5 & 2 & 1.3 & 1.8 & 2.3 & 1.6 & 2.1 & 2.6 & 1.9 & 2.4 & 2.9 \\
\hline Est. Luxemb. & 1 & 1.27 & 1.45 & 1.27 & 1.45 & 1.6 & 1.45 & 1.6 & 1.73 & 1.6 & 1.73 & 1.84 \\
\hline Est. OECD & 1 & 1.22 & 1.44 & 1.1 & 1.32 & 1.54 & 1.21 & 1.42 & 1.64 & 1.31 & 1.53 & 1.75 \\
\hline Banks/Johnson & 1 & 1.29 & 1.49 & 1.16 & 1.4 & 1.58 & 1.29 & 1.5 & 1.66 & 1.4 & 1.58 & 1.74 \\
\hline Age of children ${ }^{a}$ & 1 & 1.22 & 1.44 & 1.1 & 1.32 & 1.56 & 1.21 & 1.43 & 1.66 & 1.33 & 1.54 & 1.78 \\
\hline Role of partners ${ }^{a}$ & 1 & 1.11 & 1.37 & 1.13 & 1.24 & 1.49 & 1.26 & 1.35 & 1.61 & 1.38 & 1.48 & 1.74 \\
\hline Inc. dep. Lux. ${ }^{b}, 1000 €^{d}$ & 1 & 1.22 & 1.37 & 1.22 & 1.37 & 1.49 & 1.37 & 1.49 & 1.59 & 1.49 & 1.59 & 1.68 \\
\hline Inc. dep. Lux. ${ }^{b}, 2000 €^{d}$ & 1 & 1.32 & 1.55 & 1.32 & 1.55 & 1.73 & 1.55 & 1.73 & 1.89 & 1.73 & 1.89 & 2.04 \\
\hline Inc. dep. Lux. ${ }^{b}, 3000 €^{d}$ & 1 & 1.38 & 1.66 & 1.38 & 1.66 & 1.89 & 1.66 & 1.89 & 2.1 & 1.89 & 2.1 & 2.28 \\
\hline Inc. dep. Lux. ${ }^{c}, 1000 €^{d}$ & 1 & 1.22 & 1.37 & 1.22 & 1.37 & 1.49 & 1.37 & 1.49 & 1.59 & 1.49 & 1.59 & 1.67 \\
\hline Inc. dep. Lux. ${ }^{c}, 2000 €^{d}$ & 1 & 1.29 & 1.49 & 1.29 & 1.49 & 1.66 & 1.49 & 1.66 & 1.8 & 1.66 & 1.8 & 1.92 \\
\hline Inc. dep. Lux. ${ }^{c}, 3000 €^{d}$ & 1 & 1.36 & 1.62 & 1.36 & 1.62 & 1.84 & 1.62 & 1.84 & 2.03 & 1.84 & 2.03 & 2.2 \\
\hline Inc. dep. OECD, $1000 €^{d}$ & 1 & 1.13 & 1.28 & 1.19 & 1.32 & 1.49 & 1.38 & 1.51 & 1.68 & 1.57 & 1.7 & 1.88 \\
\hline Inc. dep. OECD, $2000 €^{d}$ & 1 & 1.25 & 1.48 & 1.11 & 1.37 & 1.54 & 1.23 & 1.48 & 1.64 & 1.34 & 1.6 & 1.73 \\
\hline Inc. dep. OECD, $3000 €^{d}$ & 1 & 1.37 & 1.68 & 1.04 & 1.41 & 1.59 & 1.08 & 1.45 & 1.6 & 1.11 & 1.49 & 1.59 \\
\hline
\end{tabular}

Source: SOEP, own calculations, e.g. A2C1=two adults, one child, ${ }^{a}=$ average scale, ${ }^{b}=\log$-linear, ${ }^{c}=$ linear, ${ }^{d}=$ equivalent income 
Table 8 - Consequences for measured inequality and poverty for the year 2004 (based on estimates for 2002 to 2006)

\begin{tabular}{|c|c|c|c|c|c|c|}
\hline Equiv. scale & Mean & Median $^{a}$ & Pov.rate & Gini & mld & Theil \\
\hline Luxembourg & 1495.17 & 1319.79 & 11.25 & .2627 & .1184 & .1307 \\
\hline OECD & 1386.17 & 1218.27 & 11.24 & .2634 & .1186 & .1315 \\
\hline Est. Luxemb. & 1725.90 & 1560.77 & 12.33 & .2645 & .1209 & .1315 \\
\hline Est. OECD & 1797.45 & 1624.36 & 12.07 & .2645 & .1212 & .1311 \\
\hline Banks/Johnson & 1736.51 & 1576.75 & 12.14 & .2627 & .1194 & .1295 \\
\hline Age of children & 1791.35 & 1620.46 & 12.12 & .2643 & .1210 & .1309 \\
\hline Role of partners & 1897.54 & 1702.34 & 13.35 & .2721 & .1283 & .1376 \\
\hline Inc. dep. Lux. ${ }^{c}$ & 1654.25 & 1544.03 & 10.36 & .2338 & .0952 & .1011 \\
\hline Inc. dep. Lux. ${ }^{d}$ & 1579.59 & 1522.84 & 10.89 & .2340 & .0953 & .0961 \\
\hline Inc. dep. OECD & 1626.77 & 1570.15 & 10.56 & .2311 & .0937 & .0944 \\
\hline
\end{tabular}

Source: SOEP, own calculations, whole population, including children ${ }^{a}=$ Euros, ${ }^{b}=$ poverty line is 60 percent of median, ${ }^{c}=\log$-linear, ${ }^{d}=$ linear, 


\section{Appendix}

Table 9 - Standard scales, detailed regression results, 2005-09

\begin{tabular}{|c|c|c|c|c|}
\hline & Luxembourg & OECD & \multicolumn{2}{|c|}{ Banks/Johnson } \\
\hline$\gamma$ & $.974 \quad(.052)$ & $.973 \quad(.052)$ & .978 & $(.052)$ \\
\hline$\alpha$ & $.281 \quad(.049)$ & & .305 & $(.051)$ \\
\hline$a$ & & $.165 \quad(.035)$ & & \\
\hline$b$ & & $.076 \quad(.042)$ & & \\
\hline$\eta$ & & & .408 & $(.266)$ \\
\hline$\Delta d_{2005}$ & $-.011 \quad(.020)$ & $-.012 \quad(.020)$ & -.012 & $(.020)$ \\
\hline$\Delta d_{2006}$ & $-.095 \quad(.032)$ & $-.097 \quad(.032)$ & -.096 & $(.032)$ \\
\hline$\Delta d_{2007}$ & $-.119 \quad(.044)$ & $-.122 \quad(.044)$ & -.121 & $(.044)$ \\
\hline$\Delta d_{2008}$ & $-.125 \quad(.057)$ & $-.128 \quad(.057)$ & -.127 & $(.057)$ \\
\hline$\Delta d_{2009}$ & $-.127 \quad(.070)$ & $-.131 \quad(.071)$ & -.130 & $(.071)$ \\
\hline 2nd quartile & $.101 \quad(.040)$ & $.101 \quad(.040)$ & .102 & $(.040)$ \\
\hline 3rd quartile & $.200 \quad(.052)$ & $.200 \quad(.052)$ & .201 & $(.052)$ \\
\hline 4th quartile & $.229 \quad(.064)$ & $.232 \quad(.064)$ & .231 & $(.064)$ \\
\hline$\Delta$ unemployed & $-.795 \quad(.040)$ & $-.797 \quad(.040)$ & -.796 & $(.040)$ \\
\hline$\Delta$ unempl. oth. & $-.246 \quad(.035)$ & $-.245 \quad(.035)$ & -.245 & $(.035)$ \\
\hline$\Delta$ part time & $-.116 \quad(.031)$ & $-.117 \quad(.031)$ & -.117 & $(.031)$ \\
\hline$\Delta \mathrm{age}^{2}$ & $2 e-3 \quad(1 e-3)$ & $2 e-3 \quad(1 e-3)$ & $2 e-3$ & $(1 e-3)$ \\
\hline$\Delta$ in education & $-.213 \quad(.038)$ & $-.213 \quad(.038)$ & -.213 & $(.038)$ \\
\hline$\Delta$ out of lab. force & $-.448 \quad(.044)$ & $-.454 \quad(.044)$ & -.453 & $(.044)$ \\
\hline$\Delta$ days ill prev. yr. & $-9 e-3 \quad(3 e-3)$ & $-9 e-3 \quad(3 e-3)$ & $-9 e-3$ & $(3 e-3)$ \\
\hline Residual Sum of Squares & 289239.6 & 289239.9 & & 289224.4 \\
\hline Number of observations & 86331 & 86331 & & 86331 \\
\hline Number of clusters & 9649 & 9649 & & 9649 \\
\hline
\end{tabular}

Source: SOEP, own calculations. Nonlinear least squares estimation on pooled differences 2005 to 2009. Standard errors account for longitudinal sample design and the clustering of individuals in households. 
Table 10 - Iso-elastic specification, detailed regression results, 2005-09

\begin{tabular}{|c|c|c|c|c|}
\hline \multirow[b]{2}{*}{$\gamma$} & \multicolumn{2}{|c|}{ Luxembourg } & \multicolumn{2}{|c|}{ OECD } \\
\hline & 6.527 & $(3.168)$ & 6.101 & $(2.98)$ \\
\hline$\alpha$ & .277 & $(.051)$ & & \\
\hline$a$ & & & 151 & $(.037)$ \\
\hline$b$ & & & .119 & $(.050)$ \\
\hline$\lambda$ & -.201 & $(.057)$ & -.253 & $(.067)$ \\
\hline$\Delta d_{2005}$ & -.011 & $(.020)$ & -.011 & $(.020)$ \\
\hline$\Delta d_{2006}$ & -.093 & $(.032)$ & -.096 & $(.032)$ \\
\hline$\Delta d_{2007}$ & -.116 & $(.044)$ & -.121 & $(.044)$ \\
\hline$\Delta d_{2008}$ & -.119 & $(.057)$ & -.127 & $(.057)$ \\
\hline$\Delta d_{2009}$ & -.123 & $(.071)$ & -.126 & $(.071)$ \\
\hline 2nd quartile & .074 & $(.040)$ & .075 & $(.040)$ \\
\hline 3rd quartile & .182 & $(.052)$ & .184 & $(.052)$ \\
\hline 4th quartile & .243 & $(.063)$ & 245 & $(.063)$ \\
\hline$\Delta$ unemployed & -.790 & $(.040)$ & -.791 & $(.040)$ \\
\hline$\Delta$ unempl. oth. & -.249 & $(.035)$ & -.248 & $(.035)$ \\
\hline$\Delta$ part time & -.118 & $(.031)$ & -.119 & $(.031)$ \\
\hline$\Delta$ age $^{2}$ & $2 e-3$ & $(1 \mathrm{e}-3)$ & $2 e-3$ & $(1 e-3)$ \\
\hline$\Delta$ in education & -.211 & $(.039)$ & -.212 & $(.039)$ \\
\hline$\Delta$ out of lab. force & -.448 & $(.044)$ & -.450 & $(.044)$ \\
\hline$\Delta$ days ill prev. yr. & $-9 e-3$ & $(3 e-3)$ & $-9 e-3$ & $(3 e-3)$ \\
\hline Residual Sum of Squares & & 289066.8 & & 289087.2 \\
\hline Number of observations & & 86331 & & 86331 \\
\hline Number of clusters & & 9649 & & 9649 \\
\hline
\end{tabular}

Source: SOEP, own calculations. Nonlinear least squares estimation on pooled differences 2005 to 2009. Standard errors account for longitudinal sample design and the clustering of individuals in households. 
Table 11 - Household information, detailed regression results, 2005-09

\begin{tabular}{|c|c|c|c|}
\hline & Age of children & \multicolumn{2}{|c|}{ Role of partners } \\
\hline$\gamma$ & $.974 \quad(.052)$ & .971 & $(.052)$ \\
\hline$a$ & $.171 \quad(.036)$ & & \\
\hline$b_{1}$ & $.100 \quad(.048)$ & & \\
\hline$b_{2}$ & $.039 \quad(.049)$ & & \\
\hline$a_{1}$ & & .145 & $(.061)$ \\
\hline$a_{2}$ & & .170 & $(.037)$ \\
\hline$b$ & & .079 & $(.042)$ \\
\hline$\Delta d_{2005}$ & $-.012 \quad(.020)$ & -.011 & $(.020)$ \\
\hline$\Delta d_{2006}$ & $-.097 \quad(.032)$ & -.096 & $(.032)$ \\
\hline$\Delta d_{2007}$ & $(.044)$ & -.121 & $(.044)$ \\
\hline$\Delta d_{2008}$ & $(.057)$ & -.127 & $(.057)$ \\
\hline$\Delta d_{2009}$ & $(.071)$ & -.130 & $(.071)$ \\
\hline 2nd quartile & $(.040)$ & .100 & $(.040)$ \\
\hline 3rd quartile & $(.052)$ & .199 & $(.052)$ \\
\hline 4th quartile & $(.064)$ & .230 & $(.064)$ \\
\hline$\Delta$ unemployed & $(.040)$ & -.797 & $(.040)$ \\
\hline$\Delta$ unempl. oth. & $-.244 \quad(.035)$ & -.246 & $(.035)$ \\
\hline$\Delta$ part time & $(.031)$ & -.117 & $(.031)$ \\
\hline$\Delta$ age $^{2}$ & $(1 \mathrm{e}-3)$ & $3 e-3$ & $(1 e-3)$ \\
\hline$\Delta$ in education & $(.038)$ & -.213 & $(.039)$ \\
\hline$\Delta$ out of lab. force & $(.044)$ & -.454 & $(.044)$ \\
\hline$\Delta$ days ill prev. yr. & $-9 e-3 \quad(3 e-3)$ & $-9 e-3$ & $(3 e-3)$ \\
\hline Residual Sum of Squares & 289233.3 & & 289238.8 \\
\hline Number of observations & 86331 & & 86331 \\
\hline Number of clusters & 9649 & & 9649 \\
\hline
\end{tabular}

Source: SOEP, own calculations. Nonlinear least squares estimation on pooled differences 2005 to 2009. Standard errors account for longitudinal sample design and the clustering of individuals in households. 
Table 12 - Income dependency, detailed regression results, 2005-09

\begin{tabular}{|c|c|c|c|c|c|}
\hline \multirow[b]{2}{*}{$\gamma$} & $\begin{array}{l}\text { Luxembourg } \\
\text { (log-linear) }\end{array}$ & \multicolumn{2}{|c|}{$\begin{array}{l}\text { Luxembourg } \\
\text { (linear) }\end{array}$} & \multicolumn{2}{|c|}{$\begin{array}{l}\text { OECD } \\
\text { (linear) }\end{array}$} \\
\hline & $1.060 \quad(.078)$ & 1.106 & $(.068)$ & 1.152 & $(.069)$ \\
\hline$\alpha_{1}$ & $.277 \quad(.053)$ & .273 & $(.043)$ & & \\
\hline$\alpha_{2}$ & $.127 \quad(.080)$ & .069 & $(.015)$ & & \\
\hline$a_{1}$ & & & & .155 & $(.030)$ \\
\hline$a_{2}$ & & & & .104 & $(.018)$ \\
\hline$b_{1}$ & & & & .109 & $(.040)$ \\
\hline$b_{2}$ & & & & -.042 & $(.014)$ \\
\hline$\Delta d_{2005}$ & $-.012 \quad(.020)$ & -.014 & $(.020)$ & -.014 & $(.020)$ \\
\hline$\Delta d_{2006}$ & $-.097 \quad(.032)$ & -.099 & $(.032)$ & -.100 & $(.032)$ \\
\hline$\Delta d_{2007}$ & $-.122 \quad(.044)$ & -.131 & $(.044)$ & -.138 & $(.044)$ \\
\hline$\Delta d_{2008}$ & $-.128 \quad(.057)$ & -.132 & $(.057)$ & -.134 & $(.057)$ \\
\hline$\Delta d_{2009}$ & $.131 \quad(.070)$ & -.135 & $(.070)$ & -.137 & $(.071)$ \\
\hline 2nd quartile & $.098 \quad(.040)$ & .069 & $(.041)$ & .064 & $(.041)$ \\
\hline 3rd quartile & $.204 \quad(.051)$ & .160 & $(.054)$ & .160 & $(.053)$ \\
\hline 4th quartile & $.245 \quad(.063)$ & .201 & $(.065)$ & .216 & $(.064)$ \\
\hline$\Delta$ unemployed & $-.793 \quad(.040)$ & -.791 & $(.040)$ & -.790 & $(.040)$ \\
\hline$\Delta$ unempl. oth. & $-.249 \quad(.035)$ & -.249 & $(.035)$ & -.252 & $(.035)$ \\
\hline$\Delta$ part time & $-.115 \quad(.031)$ & -.116 & $(.031)$ & -.118 & $(.031)$ \\
\hline$\Delta \mathrm{age}^{2}$ & $2 e-3 \quad(1 e-3)$ & $2 e-3$ & $(1 \mathrm{e}-3)$ & $2 e-3$ & $(1 e-3)$ \\
\hline$\Delta$ in education & $-.210 \quad(.039)$ & -.211 & $(.039)$ & -.211 & $(.039)$ \\
\hline$\Delta$ out of lab. force & $-.448 \quad(.044)$ & -.447 & $(.044)$ & -.449 & $(.044)$ \\
\hline$\Delta$ days ill prev. yr. & $-9 e-3 \quad(3 e-3)$ & $-8 e-3$ & $(3 e-3)$ & $-9 e-3$ & $(3 e-3)$ \\
\hline Residual Sum of Squares & 289213.3 & & - & & - \\
\hline Number of observations & 86331 & & 86331 & & 86331 \\
\hline Number of clusters & 9649 & & 9649 & & 9649 \\
\hline
\end{tabular}

Source: SOEP, own calculations. Nonlinear least squares estimation on pooled differences 2005 to 2009. Standard errors account for longitudinal sample design and the clustering of individuals in households. 